\title{
Experiences of using an interactive audience response system in lectures
}

\author{
Matti Uhari*1, Marjo Renko ${ }^{1}$ and Hannu Soini ${ }^{2}$
}

Address: ${ }^{1}$ The Department of Paediatrics, University of Oulu, FIN-90014 University of Oulu, Finland and ${ }^{2}$ Behavioural Sciences, University of Oulu, FIN-90014 University of Oulu, Finland

Email: Matti Uhari* - matti.uhari@oulu.fi; Marjo Renko - marjo.renko@oulu.fi; Hannu Soini - Hannu.soini@oulu.fi

${ }^{*}$ Corresponding author

Published: 17 December 2003

BMC Medical Education 2003, 3:12
Received: 12 September 2003

Accepted: 17 December 2003

This article is available from: http://www.biomedcentral.com/1472-6920/3//2

(C) 2003 Uhari et al; licensee BioMed Central Ltd. This is an Open Access article: verbatim copying and redistribution of this article are permitted in all media for any purpose, provided this notice is preserved along with the article's original URL.

\begin{abstract}
Background: Lectures are good for presenting information and providing explanations, but because they lack active participation they have been neglected.

Methods: Students' experiences were evaluated after exposing them to the use of voting during lectures in their paediatrics course. Questions were delivered to the students taking paediatrics course. Thirty-six students out of the total of $40(90 \%)$ attended the opening lecture, at which the first survey concerning previous experiences of lectures was performed. Thirty-nine students (98\%) answered the second series of questions at the end of the paediatrics course.

Results: Most of the students felt that voting improved their activity during lectures, enhanced their learning, and that it was easier to make questions during lectures than earlier.

Conclusions: The students gained new, exciting insights much more often during the paediatrics course than before. We as teachers found that voting during lectures could easily overcome some of the obstacles of good lecturing.
\end{abstract}

\section{Background}

Lecturing is a much used teaching method because it is an economical and efficient method of conveying information to large groups of students. Didactically, lectures are good for presenting information and providing explanations, but because they lack active participation they have been neglected, especially as active participation has become the dominant postulate of student learning. It has even been suggested that lectures should be steered towards problem-based learning for large groups $[1,2]$.

Students criticise lectures because they may be boring, or even useless when given badly. It has been suggested that only one tenth of what the lecturer is teaching is assimilated by the students [3]. Lecturing is not a good method for all teaching purposes. Clinical problem solving, for example, is more effectively taught in group sessions [4]. Yet lectures are at least as effective as other methods of teaching [5]. An AMEE guide for lectures was published recently to revive the art of lecturing [5], and we believe that instead of criticising lectures, the reasons for criticism should be analysed and this information used to improve lectures. We have been using voting with individual digital response transmitters during our paediatrics course to improve our responsiveness to the audience and to increase students' active participation. We report here on our experiences with this approach. 


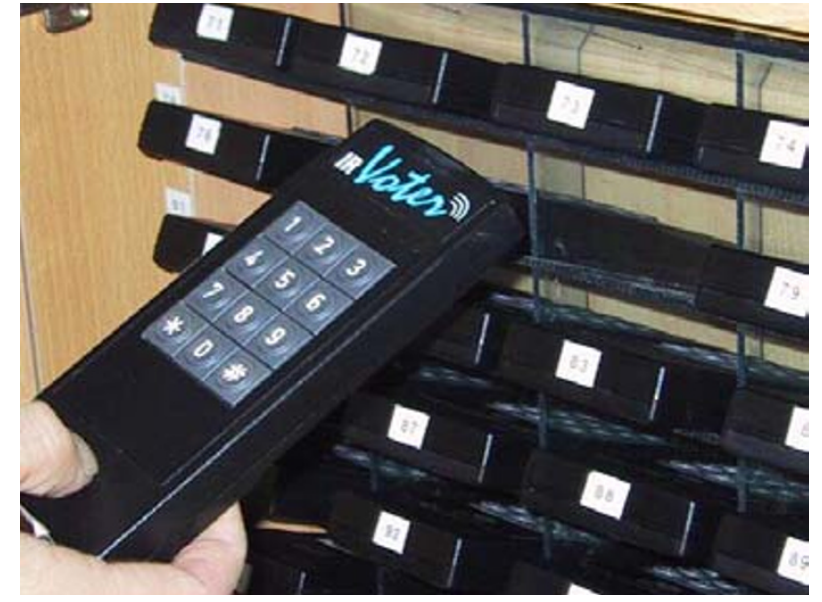

\section{Figure I}

The transmitters are kept in a locker in the lecture room which is opened before the lecture. Students pick them up as they enter the room and return them after the lecture. Each transmitter is numbered.

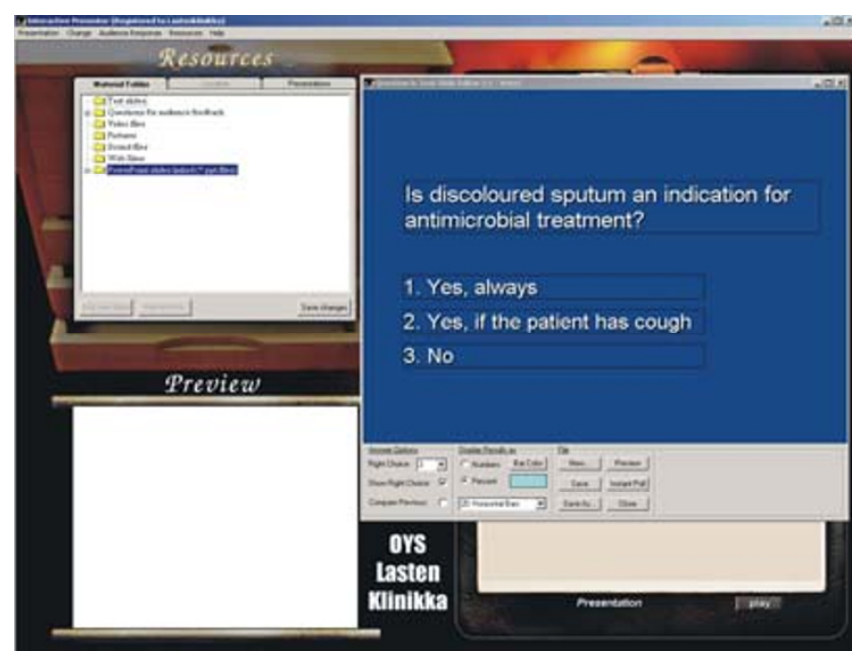

Figure 2

The PC-based software interface of the voting device. The play list includes PowerPoint files and questions, which can be written with the software or imported from a text editor.

\section{Methods}

We purchased a voting system (Interactive Presenter ${ }^{\circledR}$, Dolphin Interactive Ltd, Finland, http://www.interac tivepresenter.com) three years ago and have used it regularly both in our undergraduate and postgraduate teaching and in our meetings to the staff of our department. In addition to the voting system a computer with a data pro-

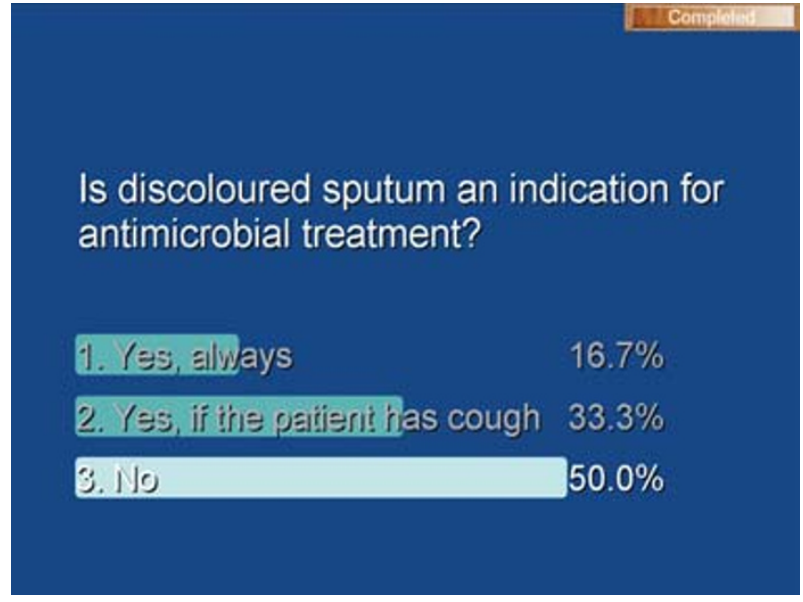

Figure 3

A question and its alternative answers can be shown to the whole audience, with voting percentages and the right answer highlighted if desired.

jector is needed. The costs of the system depend on the number of transmitters for the students and on the quality of computer and data projector. We did not have any additional costs of the use of the system. At the time we purchased the system we could have bought six well equipped microcomputers at the same price. The device includes a fixed infrared receiver on the wall of the lecture room that is connected to a computer, also in the lecture room. Each student picks up a transmitter from a box when arriving in the lecture room (Figure 1). The PCbased software interface allows the teacher to construct the lecture using PowerPoint slides, www addresses and videos and to add questions between the slides (Figure 2). The students' answers are shown to the audience under each question and presented as bars or as percentages. The right answer, if there is one, can be highlighted (Figure 3). The voting device allows multiple choice questions with from 0 to 9 alternatives to be used and each respondent can select only one answer. The whole teaching staff was trained to use the voting device during a half day session. After that some personal guidance and support from other teachers were needed. Four of six teachers adopted the method and used it during 33 lectures out of the total of 63 forty-five minutes lectures given in our paediatrics course.

The students attending our paediatrics course are in their fifth year of medical studies. The course lasts ten weeks and is held twice a year, with about 40 to 50 students on each occasion. All the teachers use a data projector and PowerPoint for audio-visual purposes. This has enabled 


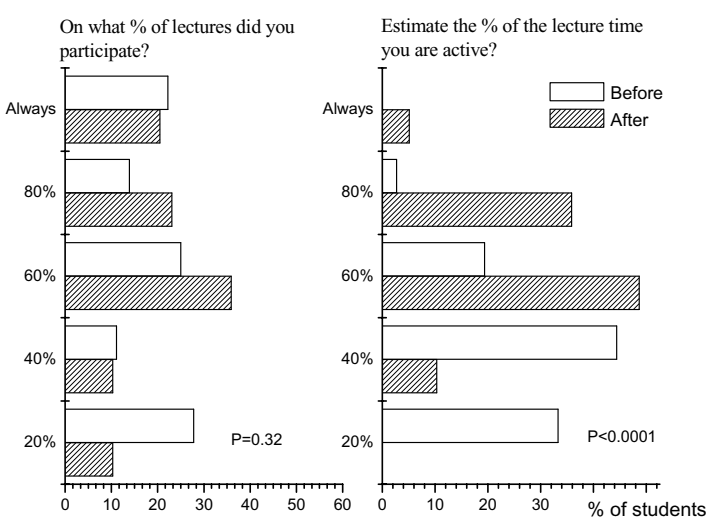

\section{Figure 4}

Student attendance and activity in lectures. The $\mathrm{x}$-axis shows the percentages of students giving the respective estimates of their attendance at lectures or their activity during them. Questions were asked immediately before (Before) and after (After) the paediatrics course of 40 students in the spring 2002.

us to produce a booklet of handouts which is given to the students at the beginning of each course [6].

We asked the students attending the paediatrics course in the spring 2002 sixteen questions about lecturing during the first introductory lecture of the course. We repeated 15 of them at the end of the course and asked three more questions specifically about the voting practice during the preceding paediatrics course. Since the same experience was asked in more than one way we report here the results only of the 12 unique responses. To ensure true answers the students responded anonymously. The students were not informed that we were interested in voting per se but merely on their experiences on lecturing in general. The questions were put before them using the voting device but without commenting on their answers, to avoid any interference due to the survey itself. However, because of these arrangements we were only able to use the unpaired chi-square test in the analyses even though each student answered twice and the responses were actually paired. Hence the results of the statistical tests should be treated with caution.

\section{Results}

Four of the six lecturers used the voting system in 33 lecture hours (52\% of the total). The usual number of questions during a 45 minutes lecture was six. Thirty-six students out of the total of $40(90 \%)$ attended the open- ing lecture, at which the first survey concerning previous experiences of lectures was performed. Thirty-nine students (98\%) answered the second series of questions at the end of the course.

Students attended actively in the lectures, since $80 \%$ of them attended on more than $60 \%$ of the occasions. This level of activity did not change significantly during the course. The students estimated that they had been active less than half of the time during previous lecture courses, but their activity increased markedly at the paediatrics lectures (Figure 4).

Before the use of voting one quarter of the students had totally disagreed with the statement that "it is easy to ask questions during lectures", but the number of students agreeing with it increased significantly during the paediatrics course (Figure 5). Similar changes occurred in the level of learning during lectures and in their knowledge of what their fellow students thought about the topic of the lecture (Figure 5). Our prior distribution of handouts was reflected in a change in the time taken to make notes during lectures (Figure 5).

More than $80 \%$ of the students felt that voting improved their learning, and most of them felt that it enhanced questioning during lectures, although some students disagreed on this latter point (Figure 6).

Students felt that lectures helped them realize what was important. This is a finding which voting did not alter (Figure 7). Also, most of the students disagreed with the statement that there should be less lectures in the teaching of medicine, even though more than $80 \%$ had found lectures annoying or boring before the paediatrics course (Figure 7). The students gained new, exciting insights much more often during the paediatrics course than before, $23 \%$ of them got new insights often or almost always during lectures before the paediatrics course as compared to $61 \%$ after paediatrics $(\mathrm{P}<0.01$ for the difference of the proportions) (Figure 7 ).

\section{Discussion}

As teachers we found voting an exciting and useful tool for activating students during lectures, and this survey shows that the students were similarly excited about it. Our experiences were so positive that at present all the teachers are using voting during the lectures in paediatrics. The main pedagogical goal of a lecture is to convey information and explanations, and we think that this was achieved, as about $80 \%$ of the students felt that lectures enhanced their learning as compared with studying on their own. Voting did not increase the activity of the students to participate on our lectures. We think that this happened because the participation was active already before the use of voting. 

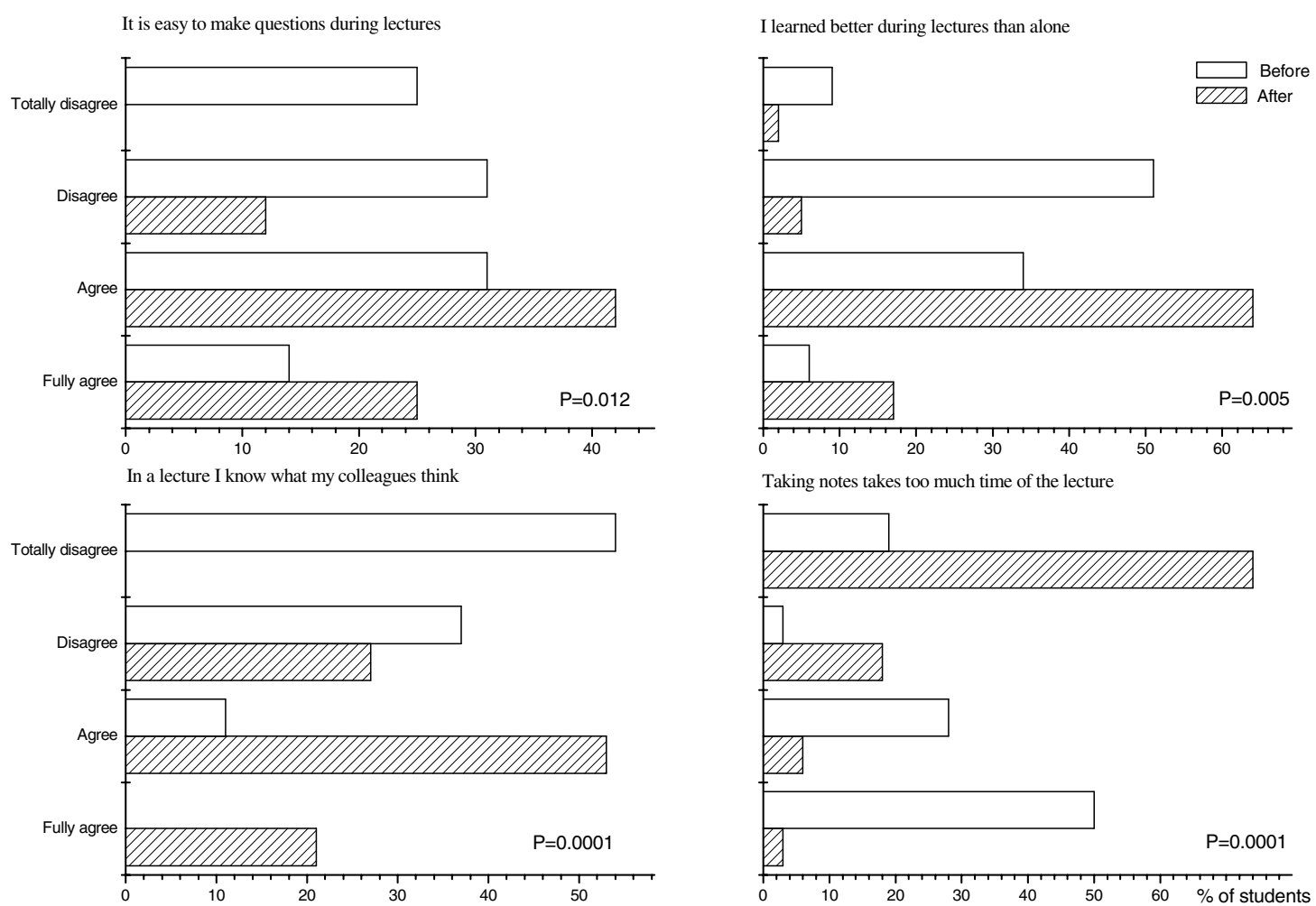

\section{Figure 5}

Percentage student responses to four statements about lecturing, and the effect of voting on these responses (before vs. after a lecture course that included voting).
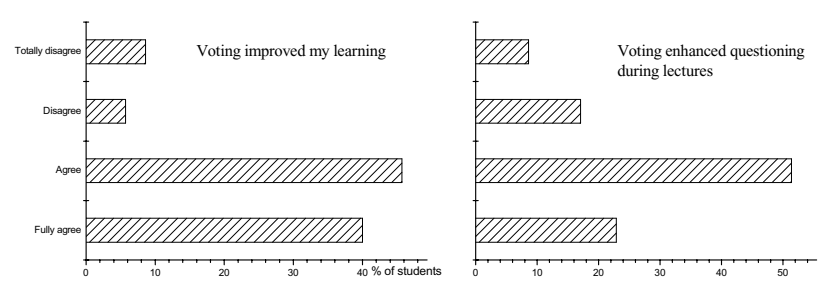

Figure 6

Student responses to statements about voting during lectures.
However, voting could increase the activity of participation in situations where it is low without any interactivity during lectures.

According to McLaughlin and Mandin [3], teachers' views of the reasons for failure in lecturing were mostly a misjudgement of the learners/context or flawed implementation of the teaching strategy. The use of voting may improve the teaching strategy, but it cannot otherwise improve a poorly organised or poorly judged lecture. Voting can help the lecturer to be organised and responsive to the students, however.

Voting can be used for several purposes. By asking questions the lecturer can find out what the students know already and can concentrate on those aspects of the topic which are not well understood. The voting system allows 

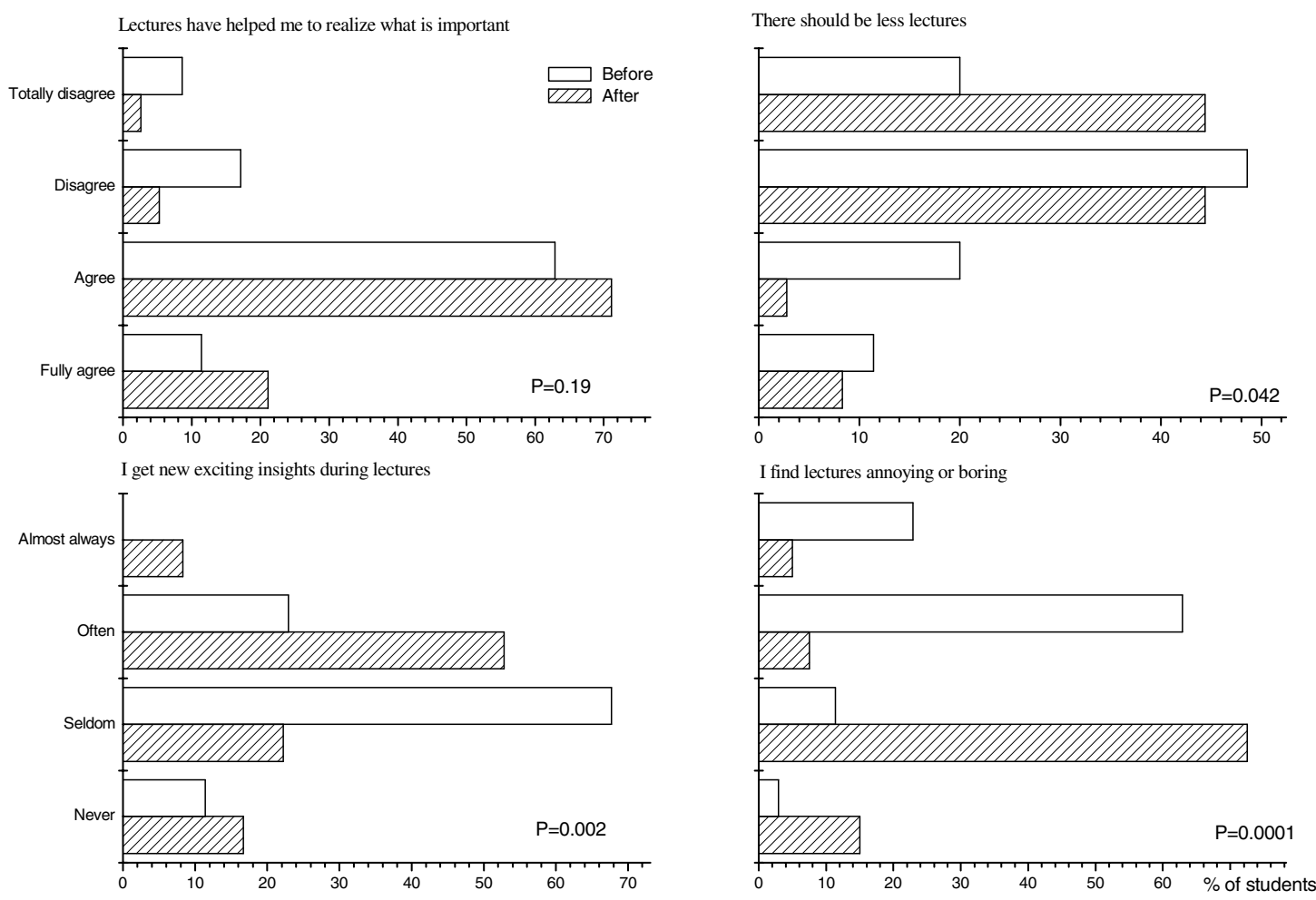

\section{Figure 7}

Percentage distribution of students' responses to statements about lecturing.

all the students to express their opinions and not only those opinion leaders who are active and brave enough to express their thoughts aloud. A lecture given with questions can be used to know students' attitudes. Without anonymous voting it is often too difficult for the students to express their attitudes, especially if they differ from those that they assume the lecturer has. In our experience voting made this possible and opened the way to useful discussions. Voting can be used for organising examinations, especially if there is no need to evaluate each student's grade but merely to give the students feedback on their knowledge for their own future use.

Students' explanations for poor lecturing include a nonresponsive lecturer, a boring lecture and a lecturer who does not provide opportunities to ask questions [3]. These are aspects which improved significantly during our course where we used voting. The validity of students' ratings when used as we did here has been found to be good [7].

New audiovisual devices make it possible to show pictures of patient cases and to improve understanding by using complex illustrations during lectures. The same devices can also be used to prepare handouts so that the students do not have to make notes and are able to concentrate on learning and to take part in voting [6]. There are several aspects which should be kept in mind when using voting [8]. First of all, the questions should be clear and easy to understand quickly. There should not be more than five alternative answers. More time should be allowed for discussions than earlier. The students in our survey reported that voting helped them to participate in discussions, and a lecturer using voting should be prepared to allow time for this. 
Even though the new technical devices provide new opportunities for teaching techniques at the same time, they also introduce new possibilities for technical problems. Thus the devices should be tested beforehand, especially if the location where the lecture is given has to be changed. Lecturers report difficulties with audiovisual devices as one important reason for the failure of lectures [3]. We have organized teaching and support for the lecturers in using the voting device. Similarly, the students should be instructed on how to use the transmitter. We found this easy and there have been no problems for the students once this has been explained.

\section{Conclusions}

Instead of merely criticising lectures, efforts should be made to improve them and attention should be paid to the reasons for the criticism. There have been surprisingly few surveys published recently on improving lecturing [9]. The AMEE medical education guide no. 22 gives excellent hints and instructions on this [5], and our present survey suggests that voting using individual digital response transmitters during lectures could easily overcome some of the obstacles.

\section{Competing interests}

None declared.

\section{Authors' contributions}

MU participated in the planning, execution, analysing and writing of the project.

MR participated in the planning, execution, analysing and writing of the project.

HS participated in the planning, analysing and writing of the project.

\section{References}

I. Joorabchi B: Construct and use a problem-based programmed lecture. Med Teach 1982, 4:6-9.

2. Georgiev G, Macpherson C, Rooney PJ: A novel extension of problem-based learning: problem-based lecture presentation by students. Med Educ 1995, 29:255-256.

3. McLaughlin $\mathrm{K}$, Mandin $\mathrm{H}$ : A schematic approach to diagnosing and resolving lecturalgia. Med Educ 200I, 35: I I35-I I 42.

4. Renko $M$, Uhari $M$, Soini $H$, Tensing $M$ : Peer consultation as a method for promoting problem-based learning during a paediatrics course. Med Teach 2002, 24:408-4 I I.

5. Brown G, Manogue M: AMEE Medical Education Guide No. 22: Refreshing lecturing: a guide for lecturers. Med Teach 2001, 23:231-244.

6. Uhari M, Rantala H: Preparing lectures using microcomputers. Med Teach 1994, 16:101-105.

7. McKeachie W,j: Student ratings. The validity of use. Am Psychol 1997, 52:1218-1225

8. Robertson L,J: Twelve tips for using a computerised interactive audience response system. Med Teach 2000, 22:237-239.

9. Nierenberg DW: The challenge of "teaching" large groups of learners: strategies to increase active participation and learning. Int J Psychiatry Med I998, 28: I I5-I 22.

\section{Pre-publication history}

The pre-publication history for this paper can be accessed here:

http://www.biomedcentral.com/1472-6920/3/12/prepub

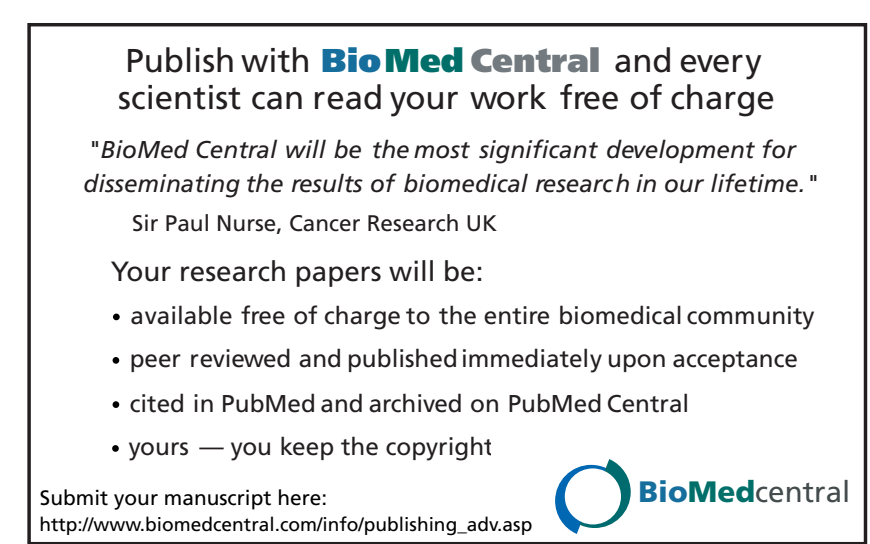

